\title{
AN AHP-BASED ORDERS-OF-MAGNITUDE APPROACH TO MUTLI- CRITERIA DECISION MAKING: PRIORITIZING DIVERGENT INTANGIBLE HUMANE ACTS
}

\author{
Jennifer S. Shang* \\ Katz Graduate School of Business \\ University of Pittsburgh \\ Pittsburgh, PA 15260 \\ E-mail: shang@katz.pitt.edu \\ Thomas L. Saaty \\ Distinguished University Professor \\ University of Pittsburgh \\ Pittsburgh, PA 15260 \\ E-mail: saaty@katz.pitt.edu
}

\begin{abstract}
An innovative Analytic Hierarchy Process-based structure is developed to capture the relationship between various levels of activities contributed by people to society. The proposed model enables one to make decisions and allocate resources in as detailed and fine a way as possible. In addition to the traditional approach of structuring criteria into multiple levels, the alternatives of a decision are also organized into the lowest multiple levels of that hierarchy. This arrangement and evaluation of alternatives differs from one criterion to another, which adds to the complexity of the undertaking when the alternatives are heterogeneous. The coherent approach to structuring complex decisions with the AHP enables one to transcend the complexity of dealing in a scientific way with the problem of widespread orders of magnitude of criteria and alternatives in a complex decision. When the magnitudes are actually very small or very large, the accuracy of rating alternatives one at a time instead of comparing them in pairs involves much guessing, and can lead to a questionable outcome. Alternatively, comparisons, which are necessary for the measurement of intangibles, have greater and better justified accuracy.
\end{abstract}

Keywords: decision support structure, Multivariate relative measurement, intangibles, AHP

\section{Introduction}

There are many factors that influence outcomes in decision making and these factors may straddle the spectrum of possibilities from the very low to the very high priorities. We often impatiently assume that we can reduce the diversity of factors into only a few - what we at a given time consider to be the important ones. But in real life, there may be numerous not-so-important determinants of an outcome, and these low-priority determinants could be collectively very influential in shaping the outcome of a decision. A serious weakness in the process of decision making to date is the mixing and reduction of all factors into a few that one habitually assumes to be the important ones.

An essential difference between what we do in this paper and what one does using traditional measurement is that in the latter, in some way, a number from a scale is assigned to each element once

${ }^{*}$ Corresponding author; Tables and Graphs are attached at the end of the paper 
and for all. In our case, measurements of objects are derived from gradual relative comparisons with respect to properties that can change from instant to instant as behavior often does, and also from problem to problem. Applying a once and for all measurement from a scale to properties that remain the same or about the same is justified for events in which the elements do not change their properties over time. However, this is not the way to do it in the measurement of multi-faceted (dynamic and transient) behavior. Thus unlike the use of traditional measurement, we need to derive measurements for not so durable objectives. As a consequence, solving a problem with relative measurement requires greater effort to layout the structure and to perform relative measurement comparisons for that problem. One has to do much more thinking to make pairwise comparisons and justify that analysis than one does when one has readymade scales with arbitrary units used uniformly to measure everything.

\subsection{A New Orders-of-Magnitude AHP Model for Comparing Heterogeneous Elements}

Traditional multi-criteria decision making methods evaluate all alternatives in a single level, which inadvertently restricts the simultaneous comparison of numerically heterogeneous alternatives. For dealing with the comparison of homogeneous elements, it is known that one cannot usually compare more than about seven homogeneous elements without increasing the overall inconsistency of the judgments. The scale used for comparing homogeneous elements in the AHP is restricted to the absolute numbers 1-9 and their reciprocals and perturbations when evaluating the relative importance of one element against another element. When one has more than seven homogenous elements to compare, one links them with a common element that is called "a pivot", and uses its measurement in both clusters to combine the measurements in the two clusters. That is also what one does to extend the use of the scale for the measurement of elements in heterogeneous clusters. By grouping alternatives into different comparison matrices and linking them through pivot alternatives, numerous alternatives on the same level but in different clusters are linked together through their priorities.

As a simple example we compare a cherry tomato with a watermelon according to size as in Figure 1. We use a process of clustering with a pivot from one cluster to an adjacent cluster that is one order of magnitude larger or smaller than the given cluster, and continue to use the 1-9 scale within each cluster to make the comparisons, and in doing that, the scale is extended as far out as desired.

\section{Figure 1 Here}

What determines the clusters is the proximity of the relative value of the priorities of the elements in each. Figure 2 shows the orders-of-magnitude AHP schema (OM-AHP) produced in the process. As usual, at the top of the model it includes a goal, followed with levels of criteria and sub-criteria. In contrast with current AHP structures, in the second half of Figure 2, the OM-AHP schema allows for multi-level alternatives. If the priority of an alternative differs by an order of magnitude or more than what is in a higher level of alternatives, it is moved below to the appropriate cluster. To do that one simply compares it with the largest priority element in that cluster and if its priority is close in magnitude, it is kept in that level. Otherwise it is moved to a level below that cluster. Note as mentioned above, a level may consist of several clusters whose elements are all homogeneous but must be grouped in clusters to make the comparisons conform to the requirement of consistency. In general, hypothetical elements may have to be introduced to make the transition from cluster to cluster a well-designed operation. The entire process stretches the imagination to deal with magnitudes and dimensions. To address the difficulty of dealing with this subject, we elaborate the procedure of OM-AHP by using the example of generous and caring activities contributed by people to society. An interesting example can be found in comparing a small gesture of kindness with the billions of dollars donations made by Bill Gates. To illustrate our model, we discuss the heterogeneous undertakings in the following section.

\section{Figure 2 Here}

\section{Identifying the Criteria and Alternatives for the OM-AHP Model Construct}

The variables used, and the values assigned to them in our example are intended to be illustrative, not final, because they need greater public participation. We propose a way of thinking that is different from our familiar imbalanced system - a system that is too heavily relied upon in our current society. 


\section{The Evaluation Criteria}

People have several basic needs. In Figure 3, we modify Maslow's (1943) hierarchy of needs to derive criteria for evaluating activities through which people make a contribution. These criteria are shown in the second level of Figure 3, and are further broken down into 12 sub-criteria, shown in the third level of the hierarchy.

\section{Figure 3 Here}

Physical needs (the $1^{\text {st }}$ criterion) are those necessary for maintaining the body strength, including food, clothing, shelter, and medical. Emotional needs are the desire of people to gain respect from others and feeling powerful. Through self-actualization, people achieve individual potential and operate at highest personal capacity.

Social needs are those that make people feel safe and draw a sense of belonging. Safety keeps people from harm. A person with a strong social network and support feels safer. Belonging needs are related to affection and being a part of a group. A helpful group member feels more integrated with society. Finally, environmental needs center on protecting the earth and its ecosystems. This includes protecting nature to maintain fresh air, clean water, and ensuring that garbage and other wastes are removed and processed in a timely manner. After identifying these pertinent evaluation criteria, we proceed to assess different types of altruistic contributions.

Altruistic Alternatives

Table 1 lists the multiple levels of altruistic activities under the evaluation criterion social needs. In ascending order of these alternatives' importance to the chosen criterion, we have: 1) Modest acts, e.g. kind gestures and small help; 2) Intermediate acts, e.g. sacrificing career, considerable time, and material wealth; and, 3) Big acts, e.g. devoting significant portions of one's life or money, and taking greater risks to serve. We divide small acts into three types, medium acts into three types, and large acts into four types. We label them as S1-S3, M1-M3, and L1-L4, respectively and list them on the leftmost column.

\section{Table 1 Here}

(A) Modest Acts - Modest acts are performed to enliven others and make people happy.

(B) Intermediate Acts - Some of the activities in this level include organizing community service to bring people together (act \#14). Providing social work and giving advice (\#17), donating moderate amounts of money (act \#18), and occasional fund raising (\#19) provide opportunities to change society on a larger scale. Beyond money, one may choose to give time to serve the public office (\#23).

(C) Big Acts - Innovation and creativity are essential for a better and brighter future. For example, breakthrough inventions are important in driving technological and social progress. The Peace Corp promotes world peace and friendship. Besides the Peace Corp, one may sacrifice for values and beliefs to work in the military, the police and fire departments, or sacrifice their lives to provide service and ask for nothing in return.

\section{Applying the New OM-AHP Model}

For each subcriterion (e.g. foods, safety, esteem needs) as listed in Figure 3, we need to identify appropriate group clusters similar to those listed in Table 1. The alternatives of each cluster are selected based on the similarity of these acts in contributing to the goal of the criterion under consideration. In Figure 4 we display the ten clusters (levels) of acts, their corresponding pairwise comparison matrices, and the local priorities of alternatives in each cluster. By comparing the elements within each cluster to derive the local priorities, we show different altruistic acts contribute to the social needs in different ways with different degrees of significance. They cannot be compared directly across clusters since the largest act would be far more important than the smallest act.

\section{Figure 4 Here}

In Figure 4 we show that we can use the results from pairwise comparisons (e.g. the ratings in the rightmost column of each matrix in Table 2), and divide them by the weight of the pivot in that cluster, and, finally, multiply them by the pivot's weight from the previous less important group to connect the 
different levels of importance. Eventually, the smallest acts, such as compliment people, end up indirectly compared with the biggest acts, such as curing global disease.

The comparisons in Table 2 are made by first comparing compliment people with all the modest acts in the same Level S1, such as acts of courtesy and agreeableness, gratitude thankfulness and honoring, etc. The act of surprising people with covert and hidden generosity is used again as the pivot in Level S2, which includes keeping company and comforting people, volunteering in library, etc. Copy all ratings derived in Table 2 to Figure 4 as local priorities (note however that in S1 the rating is shown as global priority since it's the base for all transformations). Next, we divide all the local priorities in Level S2 by the local priority of surprising people with covert \& hidden generosity (0.08), and multiply all the resulting local idealized priorities $(1,1.732,3.206,6.412)$ in this level by the global priority in Level S1 of surprising people with covert and hidden generosity (0.55) to arrive at the global priority. In the same manner, the priorities of the intermediate acts in M1, M2 and M3 are derived.

\section{Table 2 Here}

Similarly, we include the M3 act of running for political office in the big acts Level L1 cluster. We pairwise compare and synthesize the matrix in Table 2 to find the local priorities $(.096, .161, .277, .466)$ for all Level L1 acts. Next, in Figure 4, cluster L1 we derive the local ideals by dividing every local priority by the smallest local priority, 0.096 . Multiplying the local ideals $(1,1.678,2.888,4.854)$ by the global priority of running for political office $(45,080)$ in the intermediate acts Level M3, we obtain the global priorities for all cluster L1 acts. Similarly, we obtain the global priorities of the cluster L4 acts as $5384577,10832968,26533253$, and 68755097 . In the end, we normalize all acts in S1 by dividing each act by the global priority of the smallest act, 0.06 (acts of complimenting people in S1). Link them group by group. Eventually, global ideals are obtained for modest acts $\mathrm{S} 1=(1.00,1.7,5.07,9.39), \mathrm{S} 2=(9.39$, $16.266,30.115,60)$; and $\mathrm{S} 3=(60,110,203,306,595)$. For intermediate acts $\mathrm{M} 1=(595,1125,1934$, $3619,5028,7376), \mathrm{M} 2=(7376,18446,29728,46115,78890)$, and $\mathrm{M} 3=(78890,169003,365185$, 773639). For big acts L1 $=(773639,1298430,2234102,3755093), \mathrm{L} 2=(3755093,7840304,17124874)$, $\mathrm{L} 3=(17124874,33345464,92406497)$, and $\mathrm{L} 4=(92406497,185908141,455345908,1179928909)$. For the other three criteria listed in Figure 3, we have built the similar sub-structures with different cluster membership, depending on their similarity in contributing to the goal of the criterion. Details of each of the alternative comparison matrices are available in the online supplement.

By multiplying the global ideal priorities derived for each of the four criteria with the corresponding criterion weights, we are able to determine the overall final scores for each of the 33 activities. Note for example, the final value of global disease cure of $1,140,230,056$ is derived by $(1,183,020,799 *$ * $398+$ $1,179,928,909 * .206+1,115,698,094 * .285+1,037,467,931 * .1111=140,230,056)$. In this way, we have created a comparison between the smallest act compliment people and the biggest act of global disease cure. We have correspondingly extended the scale beyond 9 to 1,140,230,056. In Figure 5 we give the final score of each benevolent act, e.g. the final synthesized value of global disease cure is at $1,140,230,056$ times more important relative to compliment people in terms of satisfying human needs.

\section{Figure 5 Here}

The grouping or clustering approach adopted here is critical. In most decision problems, there may be two or three groups that differ by orders of magnitude from one another. The AHP scale does not limit us in comparing alternatives if we cluster similar objects into groups and use for a pivot the largest element in one group as the smallest element in the next group. The priorities in two adjacent groups should be sufficiently different, each being one order of magnitude smaller than the other. As a result, the ratings of the smaller set have some impact on the judgment of the larger set. Using this method, comparing a modest act with a highly respectable and noble act becomes possible. Note that the clusters of alternatives under each criterion differ since they depend on where an alternative stands respect to that criterion. This rearrangement of the alternatives has to be done several times, once for each of the criteria. Results: The Value of Benevolent Acts 
Although humaneness, international disaster relief, and community volunteerism are familiar concepts in our daily lives, there has been no openly accepted standard for appraising the value of these benevolent acts. Without an objective means to determine the monetary equivalence of intangibles, society has a hard time understanding their true worth. By the order-of-magnitude AHP model, we uncover a better approach to assign values to altruistic deeds taking place all over the world. Through our method, acts of charity can be valued for the psychological satisfaction they bring to the individuals performing the acts and they can also be assigned significance based on their level of social contribution.

In this paper, we have shown how benevolent acts can be converted into explicit value. At its extreme, we may equate dollars to priorities, or some similar variant, and then assign a relative fair market price to an act. For example, acts which involve committing a lifetime of volunteering to serve humanity, such as Mother Teresa's level and length of devotion, would be worth between $\$ 40$ and $\$ 50$ million dollars or $\$ 45,721,297$ according to our account (see Figure 5, act \#28). Investing in the cure of global disease, such as the development of a vaccine for H1N1 flu or a drug for the widespread and devastating AIDS disease killing millions of people, would be worth over a billion dollars $(\$ 1,140,230,056)$ as suggested by the global weighted score derived in our model (act \#33 in Figure 5). This value is a composite of the values derived under each criterion in which this alternative falls in a higher range of values. We must admit that this is only an illustrative example that may not be perfect, and needs judgment from a group of experts in this domain of knowledge and experience (Saaty 2007). Were we to use greater effort to do the same evaluation in terms of the sub-criteria listed in the $3^{\text {rd }}$ level of Figure 3, we would have probably obtained a more accurate representation of this very large value.

\section{Conclusions}

If one were to use a scale to rate alternatives one at a time, one would have to make the values of that scale range from zero to $10^{10}$ in some cases and it would be extremely difficult to judge accurately where the value assigned to each alternative on that scale should fall. We must often guess as to the likely outcome resulting from our decisions. This is also illustrated by the example of our depressed economy. Comparing the many small actions taken to improve the economy through decisions at the local levels with those taken through decisions at the state or the national level, would be difficult and imprecise.

To deal with intangibles scientifically, in this paper we have pairwise compared them to derive the relative priorities. Making comparisons is our biological heritage. It was there long before measurement scales were invented with their arbitrary units and gradually used in science to develop scientific theories about the physical universe. But our internal universe of values has been largely ignored. We need to identify the factors that play a significant role in shaping this internal universe to be better able to identify their significance and determine the role the influence plays leading us to the future.

The main contribution of this research is the enhancement of the AHP methodology where we illustrate an extensive system with heterogeneous elements. In the past four decades, multi-criteria decision modeling has attracted much attention. However, a distinctive area, dealing specifically with the presence of heterogeneous data, has not been explored. So far as the judgments used are concerned, it is not the measurement precision for a particular alternative that determines the validity of the evaluation results, but the importance we attach to the various criteria used to weight and synthesize those measurement that has greater impact on the outcome. Members of stakeholders need to participate in assigning importance to these factors in order to obtain the diversity of information needed to best differentiate among all acts.

\section{REFERENCES}

Economist, 2010. A Better Way: The rich world should worry about growth-promoting reforms more than short-term fiscal austerity. Retrieved November 12, 2010

http://www.economist.com/node/17173919.

Gaye, A. 2007/2008, Access to Energy and Human Development, Human Development Report 2007/2008. Fighting climate change: Human solidarity in a divided world, United Nations Development 
Program. Retrieved November 12, 2010. http://hdr.undp.org/en/reports/global/hdr20072008/papers/gaye_amie.pdf.

Giving USA 2009: The Annual Report on Philanthropy for the Year 2008, Retrieved Dec. 3, 2010, http://www.aafrc.org/gusa/gusa_order.cfm and http://www.philanthropy.iupui.edu/News/2009/docs/GivingReaches300billion_06102009.pdf.

Hubbard, D. W. 2007, How to Measure Anything: Finding the Value of "Intangibles" in Business, John Wiley \& Son, Hoboken, NJ.

Kurzweil, R (2005) The singularity is near. Penguin Books, New York.

Kostigen, T. 2009, The happiest taxes on earth. Retrieved September 21, 2009, http://www.marketwatch.com/story/the-happiest-places-on-earth-are-heavily-taxed.

Maslow, A.H. 1943, A Theory of Human Motivation, Psychological Review, 50(4), 370-96.

Millet, I. and Saaty, T.L. 2000, On the relativity of relative measures - accommodating both rank preservation and rank reversals in the AHP," European Journal of Operational Research, 121(1), 205-212.

Ozdemir, M.S. and T.L. Saaty, 2006, The Unknown in Decision Making: What to do about it? European Journal of Operational Research, 174 (1), 349-359

Saaty, T.L. and M. Takizawa, 1986, "Dependence and Independence: From Linear Hierarchies to Nonlinear Networks, European Journal of Operational Research, 26(2), 229-237.

Saaty, T.L. 1994a, Homogeneity and Clustering in AHP Ensure the Validity of the Scale", European Journal of Operational Research, 72(3), 598-601

Saaty, T.L. 1994b, Highlights and Critical Points in the Theory and Application of the Analytic Hierarchy Process", European Journal of Operational Research, 74(3), 426-447

Saaty, T.L. 1996, Decision Making with Dependence and Feedback, Pittsburgh: RWS Publications

Saaty, T.L. 2001, Models, Methods, Concepts \& Applications of the Analytic Hierarchy Process, with Luis G. Vargas, Kluwer Academic

Saaty, T.L. 2003, Decision-making with the AHP: Why is the principal eigenvector necessary, European Journal of Operational Research 145(1), 85-91

Saaty, T.L. 2006, Rank from comparisons and from ratings in the analytic hierarchy/network processes, European Journal of Operational Research 168(2), 557-570

Saaty, T.L. and Peniwati, K. 2007. Group Decision Making: Drawing Out and Reconciling Differences, Pittsburgh: RWS Publications.

Samuelson, R. J. 1992, How Our American Dream Unraveled, Newsweek. Retrieved March 1, 2010, http://www.newsweek.com/id/118553.

Shang, J. and T. Sueyoshi. 1995, A Unified Framework for the Selection of a Flexible Manufacturing System, European Journal of Operational Research. 85(2), 297-310.

Starr, R.M. 1972, The Structure of Exchange in Barter and Monetary Economies, The Quarterly Journal of Economics, 86(2), 290-302.

Sueyoshi, T., J. Shang, W. Chiang (2009), A Decision Support Framework for Internal Audit Prioritization in Rental Car Company: Combined Use between DEA and AHP", European Journal of Operational Research, 199(1), 219-231

Tjader, Y. J. Shang, L. Vargas 2010, Offshore Outsourcing Decision Making: A Policy-Maker's Perspective, European Journal of Operational Research, 207(1), 2010, 434-444.

Velasquez, M., Andre, C., Shanks, T. and Meyer, S.J. and M.J. 1992, The Common Good. Retrieved November 6, 2010, http://www.scu.edu/ethics/practicing/decision/Commongood.

Yahoo, November 15 2010, http://news.yahoo.com/s/afp/britainpoliticslifestylehappiness, access November 16, 20 
Table 1. Clustering the Altruistic Acts under the Social Needs Criterion

\begin{tabular}{|c|c|c|c|c|c|c|}
\hline \multirow{2}{*}{\begin{tabular}{|l} 
Altruistic Acts Cluster type \\
Modest Acts Cluster 1 (S1)
\end{tabular}} & \multirow[b]{2}{*}{ 1.Compliment People } & \multicolumn{3}{|c|}{ Clustering the Altruistic Acts Under the Social Needs Criterion } & & \\
\hline & & $\begin{array}{l}\text { 2.Acts of Courtesy \& } \\
\text { Agreeableness (e.g. open }\end{array}$ & $\begin{array}{l}\text { 3.Gratitude Thankfulness, } \\
\text { \& Honoring }\end{array}$ & $\begin{array}{l}\text { 4.Surprise People } \\
\text { w/Generosity }\end{array}$ & & \\
\hline Modest Acts Cluster 2 (S2) & $\begin{array}{l}\text { 4.Surprise People } \\
\text { w/Generosity }\end{array}$ & $\begin{array}{l}\text { 5.Keep Company \& } \\
\text { Comfort People }\end{array}$ & 6. Help in library & $\begin{array}{l}\text { 7.Allow children to } \\
\text { shadow your job }\end{array}$ & & \\
\hline Modest Acts Cluster 3 (S3) & $\begin{array}{l}\text { 7. Allow children to shadow } \\
\text { \& learn about your job }\end{array}$ & $\begin{array}{l}\text { 8.Offer help to unpleasant } \\
\text { tasks at work }\end{array}$ & 9. Work at Food Bank & $\begin{array}{l}\text { 10.Cleaning \& Caring } \\
\text { Environment }\end{array}$ & \begin{tabular}{|l|}
11. Teaching, \\
Educating \\
Community \\
\end{tabular} & \\
\hline Intermediate Acts Cluster 1 (M1) & $\begin{array}{l}\text { 11. Volunteer at Homeless } \\
\text { Shelter }\end{array}$ & $\begin{array}{l}\text { 12.Teaching, Educating } \\
\text { Community }\end{array}$ & $\begin{array}{l}\text { 13.Community Blood } \\
\text { Drive }\end{array}$ & $\begin{array}{l}\text { 14.Organize } \\
\text { Community Service }\end{array}$ & $\begin{array}{l}\text { 15.Hospital Care } \\
\text { Program for } \\
\text { Children's Ward }\end{array}$ & $\begin{array}{l}\text { 16.Long-term } \\
\text { Help Nursing } \\
\text { Home }\end{array}$ \\
\hline Intermediate Acts Cluster 1 (M2) & $\begin{array}{l}\text { 16.Long-term Help Nursing } \\
\text { Home }\end{array}$ & $\begin{array}{l}\text { 17.Social Work \& Giving } \\
\text { Advice }\end{array}$ & \begin{tabular}{|l|} 
18.Donate Moderate \\
Amount of Money (e.g. \\
United Way, Red Cross) \\
\end{tabular} & $\begin{array}{l}\text { 19.Community Fund } \\
\text { Raising Event }\end{array}$ & $\begin{array}{l}\text { 20.Adopt } \\
\text { Disabled } \\
\text { Children } \\
\end{array}$ & \\
\hline Intermediate Acts Cluster 1 (M3) & \begin{tabular}{|l|} 
20.Adopt Disabled \\
Children \\
\end{tabular} & 21.Habitat for Humanity & $\begin{array}{l}\text { 22.Moderate Micro } \\
\text { Lending } \\
\end{array}$ & $\begin{array}{l}\text { 23.Run for Political } \\
\text { Office }\end{array}$ & & \\
\hline Big Acts Cluster 1 (L1) & 23.Run for Political Office & $\begin{array}{l}\text { 24.Military, Police, or Fire } \\
\text { Service }\end{array}$ & 25.Peace Corp & $\begin{array}{l}\text { 26.Breakthrough } \\
\text { Invention (sacrifice) }\end{array}$ & & \\
\hline Big Acts Cluster 2 (L2) & $\begin{array}{l}\text { 26.Breakthrough Invention } \\
\text { (sacrifice) }\end{array}$ & 27.Large Micro Lending & $\begin{array}{l}\text { 28.Life Time Humanity } \\
\text { Devotion (Mother } \\
\text { Teresa) }\end{array}$ & & & \\
\hline Big Acts Cluster 3 (L3) & $\begin{array}{l}\text { 28.Life Time Humanity } \\
\text { Devotion (Mother Teresa) }\end{array}$ & $\begin{array}{l}\text { 29.Sizable (tens of \$Billion) } \\
\text { Money Donation }\end{array}$ & $\begin{array}{l}\text { 30.Individual Sacrifice life } \\
\text { to save others }\end{array}$ & & & \\
\hline Big Acts Cluster 3 (L4) & $\begin{array}{l}\text { 30.Individual Sacrifice life } \\
\text { to save others }\end{array}$ & $\begin{array}{l}\text { 31.International Conflict } \\
\text { Mediation }\end{array}$ & \begin{tabular}{|l} 
32.Humanity Relief \\
Rescue (e.g. Medical)
\end{tabular} & $\begin{array}{l}\text { 33. Global Disease } \\
\text { Cure }\end{array}$ & & \\
\hline
\end{tabular}


Table 2. The Pairwise Comparisons and Local Priorities of the Altruistic Acts Under Social Needs Criterion

\begin{tabular}{|c|c|c|c|c|c|c|c|}
\hline Social Needs (S1) & 1.Compliment & 2.Acts of Courtesy \& & 3. Gratitude, & 4.Surprising People & Rating & & \\
\hline 1.Compliment People & 1 & $1 / 2$ & $1 / 6$ & $1 / 7$ & 0.058 & & \\
\hline 2.Acts of Courtesy \& & 2 & 1 & $1 / 4$ & $1 / 5$ & 0.099 & & \\
\hline 3. Gratitude, & 6 & 4 & 1 & $1 / 3$ & 0.295 & & \\
\hline 4.Surprising People & 7 & 5 & 3 & 1 & 0.547 & & \\
\hline Social Needs $(\mathbf{S} 2)$ & 4.Surprising People & 5.Keep Company \& & 6.Volunteer in library & 7. Allow children to & Rating & & \\
\hline 4.Surprising People & 1 & $1 / 2$ & $1 / 3$ & $1 / 6$ & 0.081 & & \\
\hline 5.Keep Company \& & 2 & 1 & $1 / 2$ & $1 / 4$ & 0.140 & & \\
\hline 6. Help in library & 3 & 2 & 1 & $1 / 2$ & 0.260 & & \\
\hline 7. Allow children to & 6 & 4 & 2 & 1 & 0.519 & & \\
\hline Social Needs (S3) & 7. Allow children to & 8. Offer help to & 9. Work at Food & 10.Cleaning \& & 11. Volunteer at & Rating & \\
\hline 7.Allow children to & 1 & $1 / 3$ & $1 / 4$ & $1 / 5$ & $1 / 6$ & 0.047 & \\
\hline 8.Offer help to & 3 & 1 & $1 / 3$ & $1 / 4$ & $1 / 5$ & 0.086 & \\
\hline 9. Work at Food Bank & 4 & 3 & 1 & $1 / 2$ & $1 / 4$ & 0.159 & \\
\hline 10.Cleaning \& Caring & 5 & 4 & 2 & 1 & $1 / 3$ & 0.240 & \\
\hline 11. Volunteer at & 6 & 5 & 4 & 3 & 1 & 0.467 & \\
\hline Social Needs (M1) & 11. Volunteer at & 12. Teaching, & 13.Community & 14. Organize & 15.Hospital Care & 16.Long-term Help & Rating \\
\hline 11.Volunteer at & 1 & $1 / 2$ & $1 / 3$ & $1 / 7$ & $1 / 8$ & $1 / 9$ & 0.017 \\
\hline 12. Teaching, & 2 & 1 & $1 / 2$ & $1 / 3$ & $1 / 4$ & $1 / 7$ & 0.032 \\
\hline 13.Community Blood & 3 & 2 & 1 & $1 / 2$ & $1 / 3$ & $1 / 4$ & 0.056 \\
\hline 14. Organize & 7 & 3 & 2 & 1 & $1 / 2$ & $1 / 3$ & 0.104 \\
\hline 15. Hospital Care & 8 & 4 & 3 & 2 & 1 & $1 / 2$ & 0.144 \\
\hline 16.Long-term Help & 9 & 7 & 4 & 3 & 2 & 1 & 0.212 \\
\hline Social Needs (M2) & 16.Long-term Help & 17.Social Work \& & 18.Donate Moderate & 19.Community Fund & 20.Adopt Disabled & Rating & \\
\hline 16.Long-term Help & 1 & $1 / 3$ & $1 / 4$ & $1 / 5$ & $1 / 7$ & 0.026 & \\
\hline 17. Social Work \& & 3 & 1 & $1 / 2$ & $1 / 3$ & $1 / 5$ & 0.066 & \\
\hline 18.Donate Moderate & 4 & 2 & 1 & $1 / 2$ & $1 / 4$ & 0.106 & \\
\hline 19.Community Fund & 5 & 3 & 2 & 1 & $1 / 2$ & 0.165 & \\
\hline 20.Adopt Disabled & 7 & 5 & 4 & 2 & 1 & 0.282 & \\
\hline
\end{tabular}


Table 2 (cont'd)

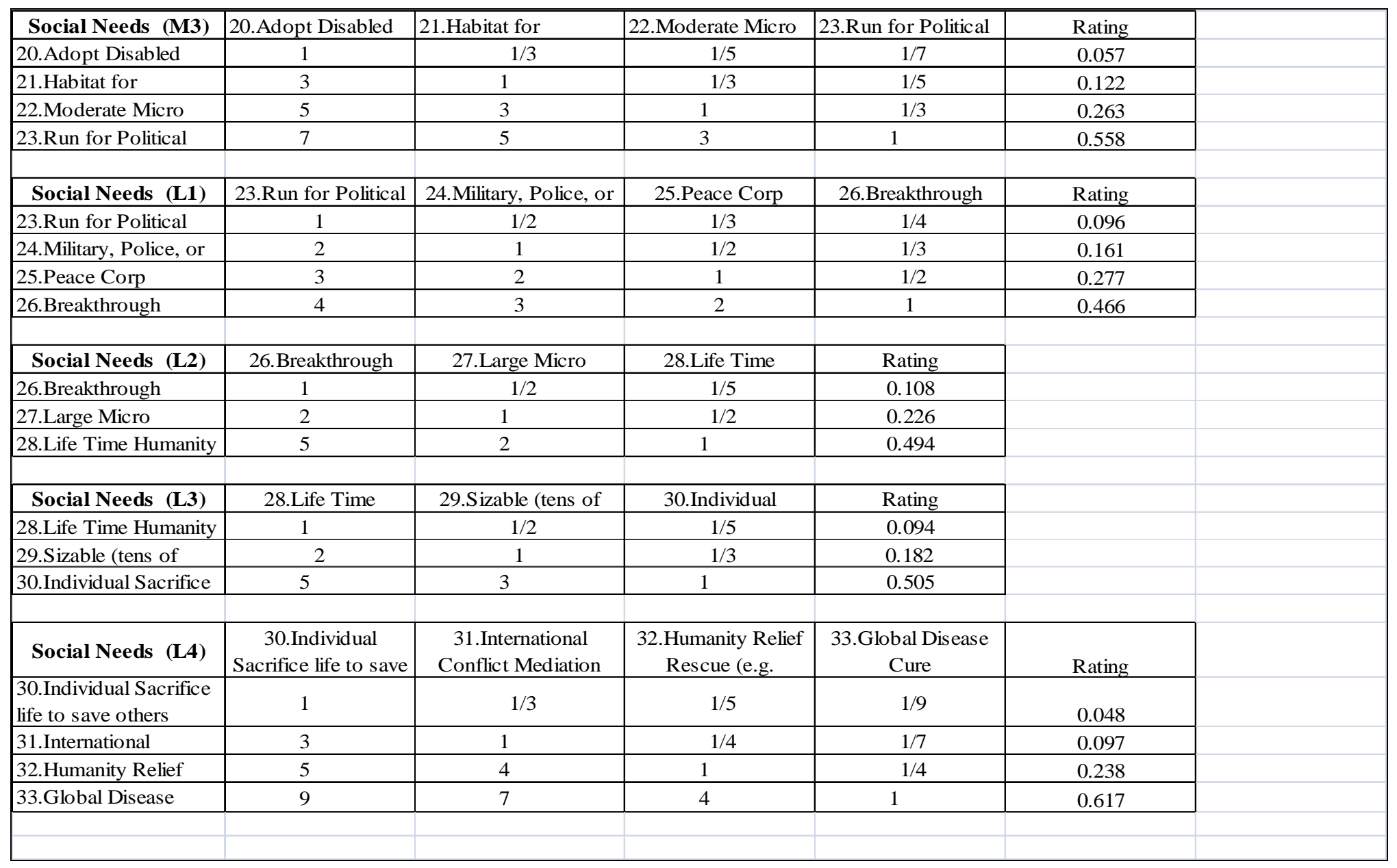


Figure 1. Clustering to Compare Non-homogeneous Objects

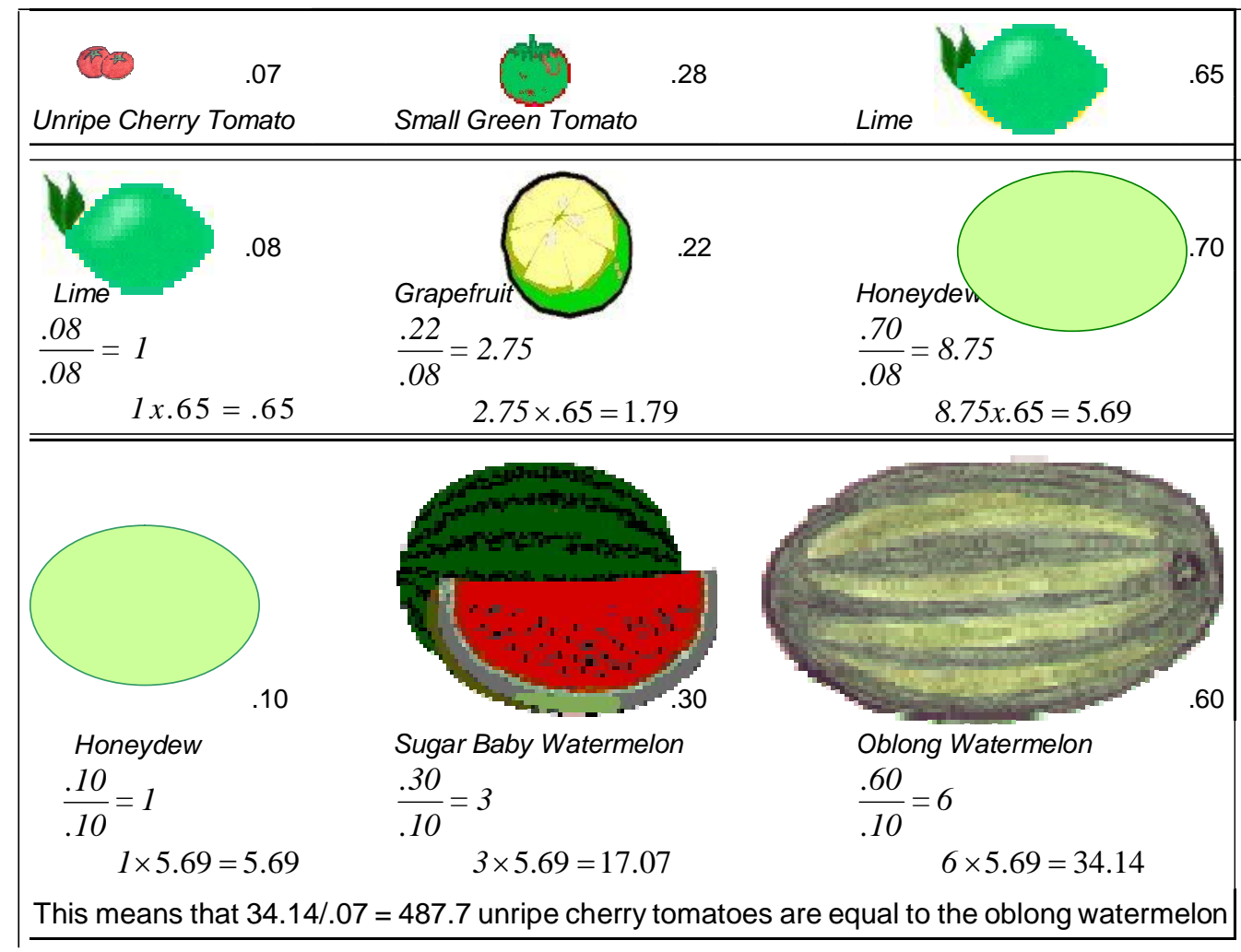


Figure 2. The Orders-of-Magnitude AHP Schema to Mutli-criteria Decision Making: Multi-Level of Criteria and Sub-criteria, with Multi-Level of Alternatives
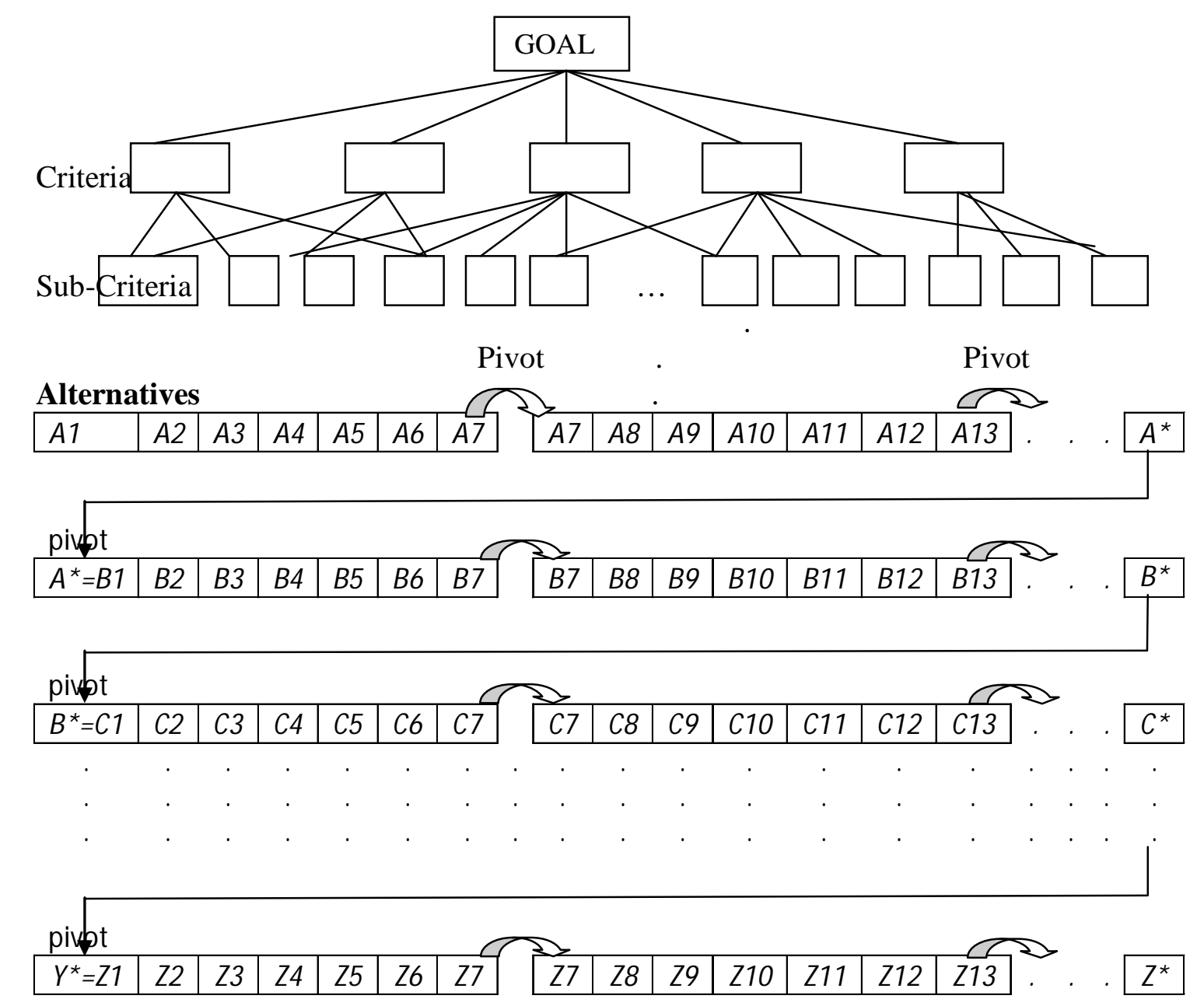

Note: The rightmost alternative with superscript " $x$ ' is the pivot alternative, which reappears as the first alternative in the next cluster. 
Figure 3. The AHP Criteria and Sub-criteria and Their Corresponding Weights for Evaluating the Contribution of the Altruistic Acts to the Wellbeing

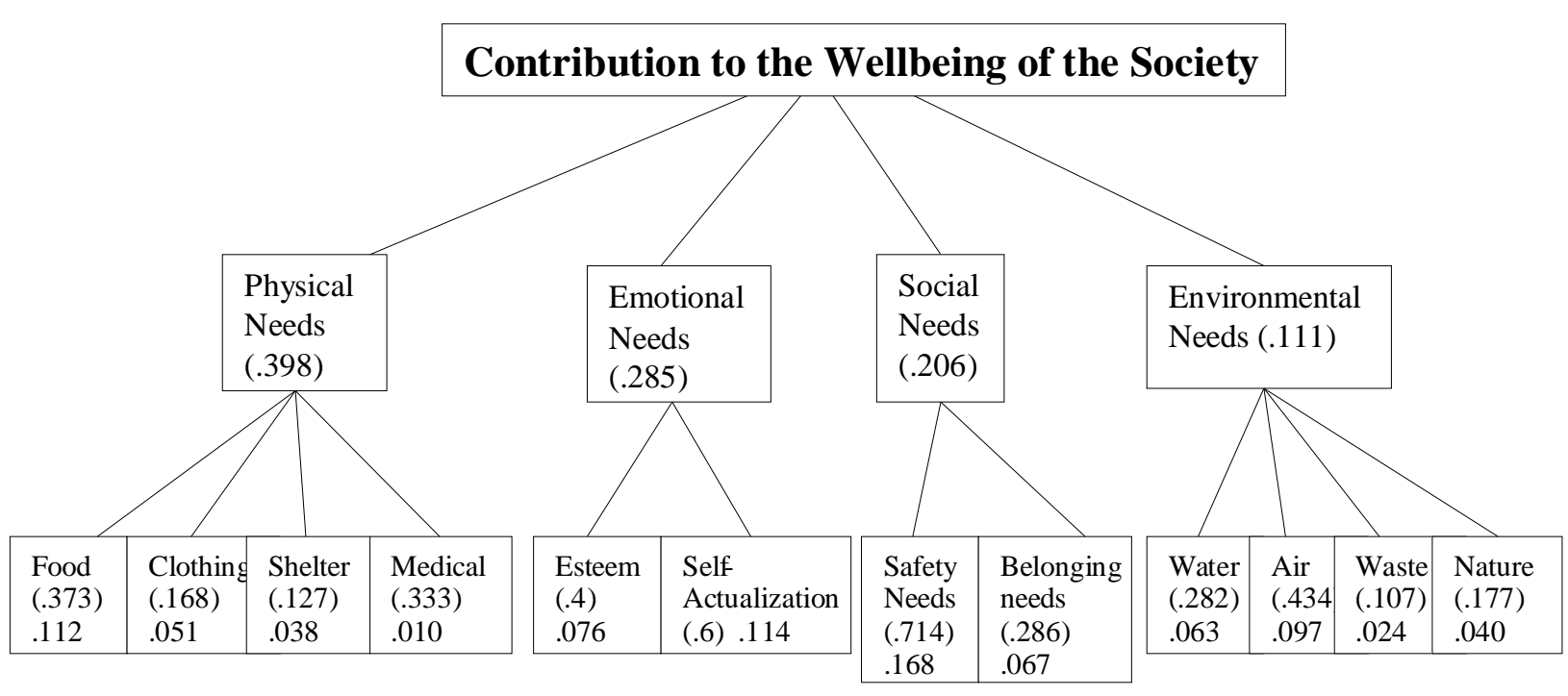


Figure 4. The AHP Model to Prioritize the Benevolent Acts Under the Social Needs

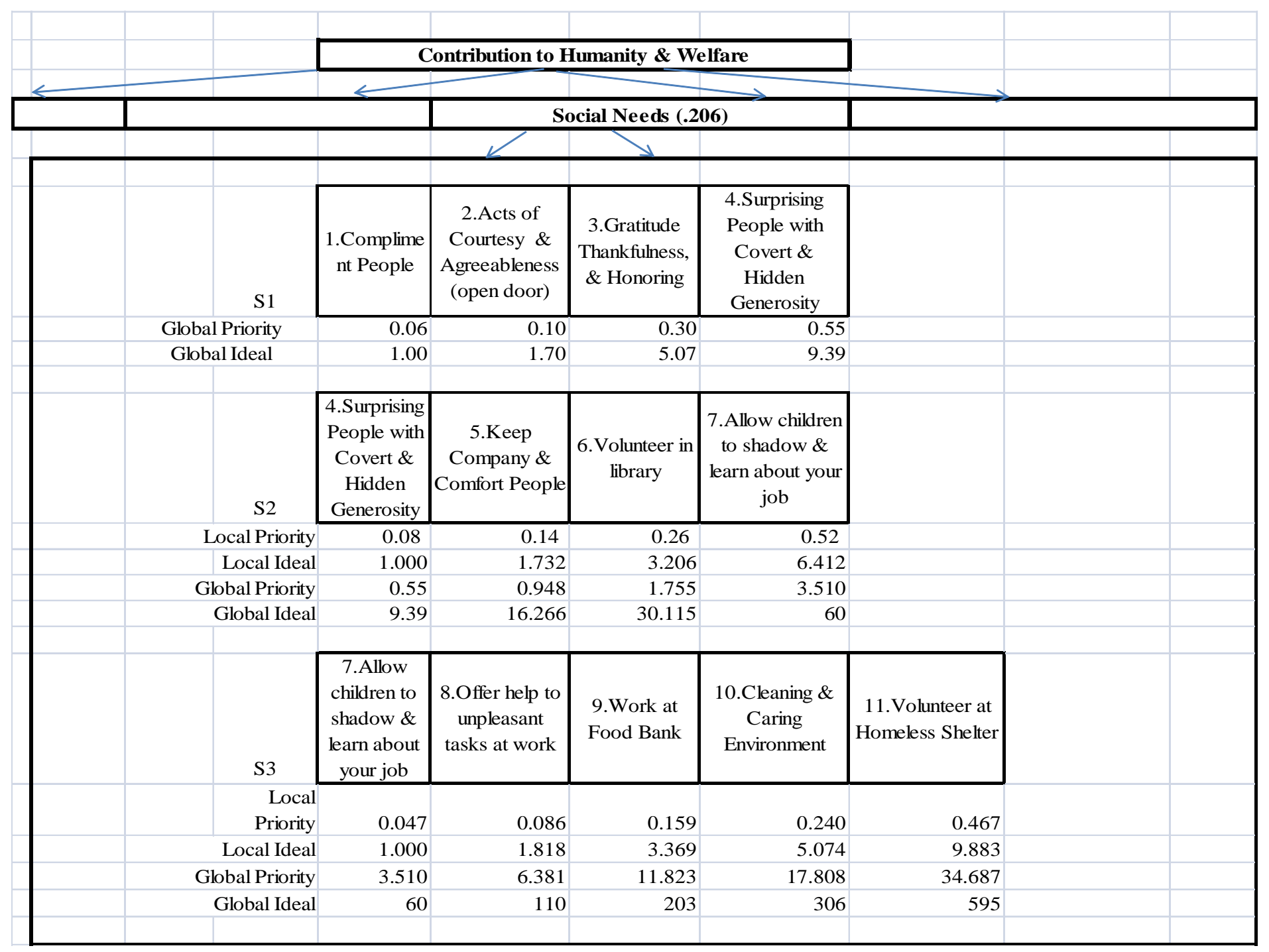


Figure 4 (Cont'd)

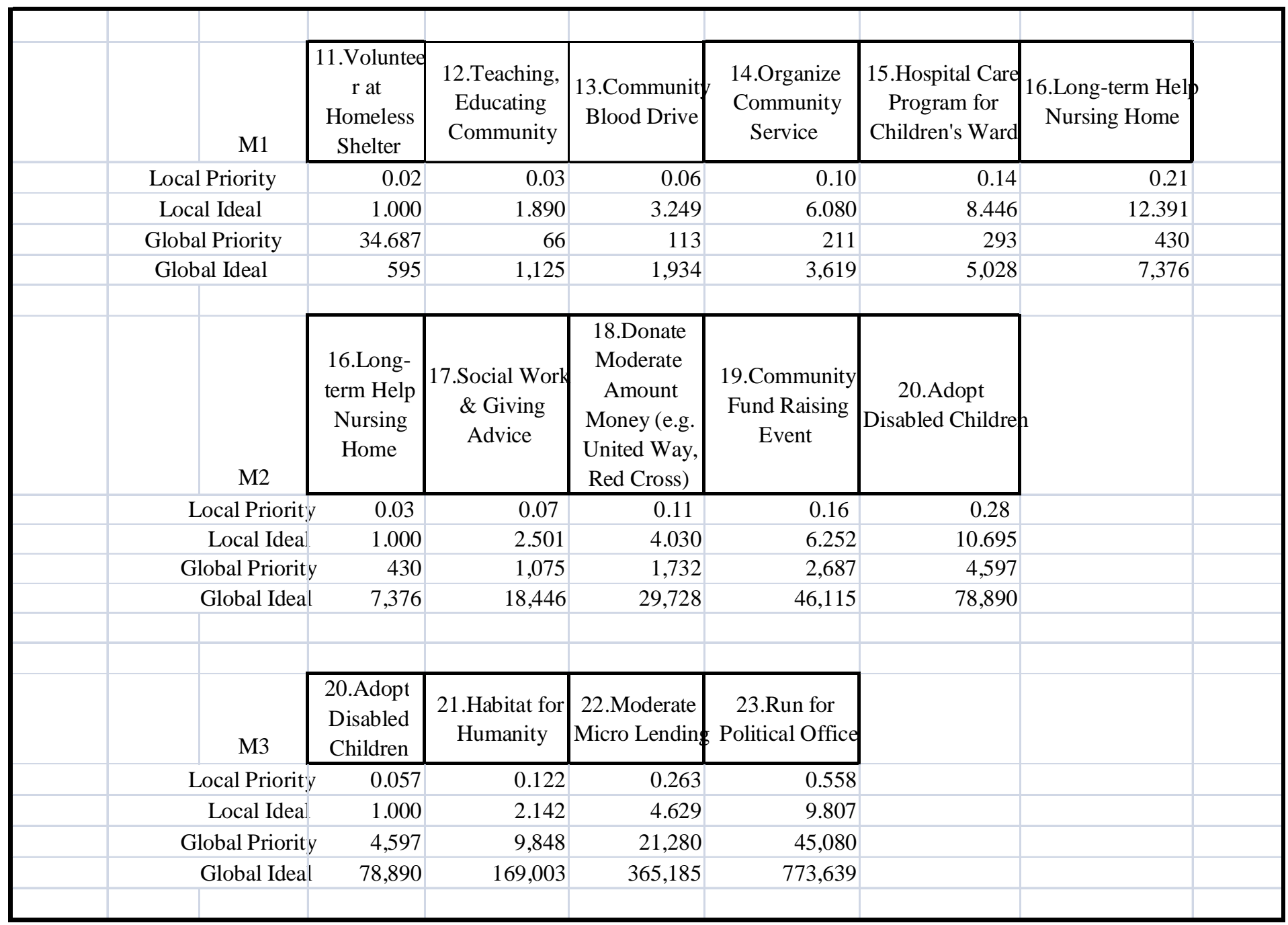


Figure 4 (Cont'd)

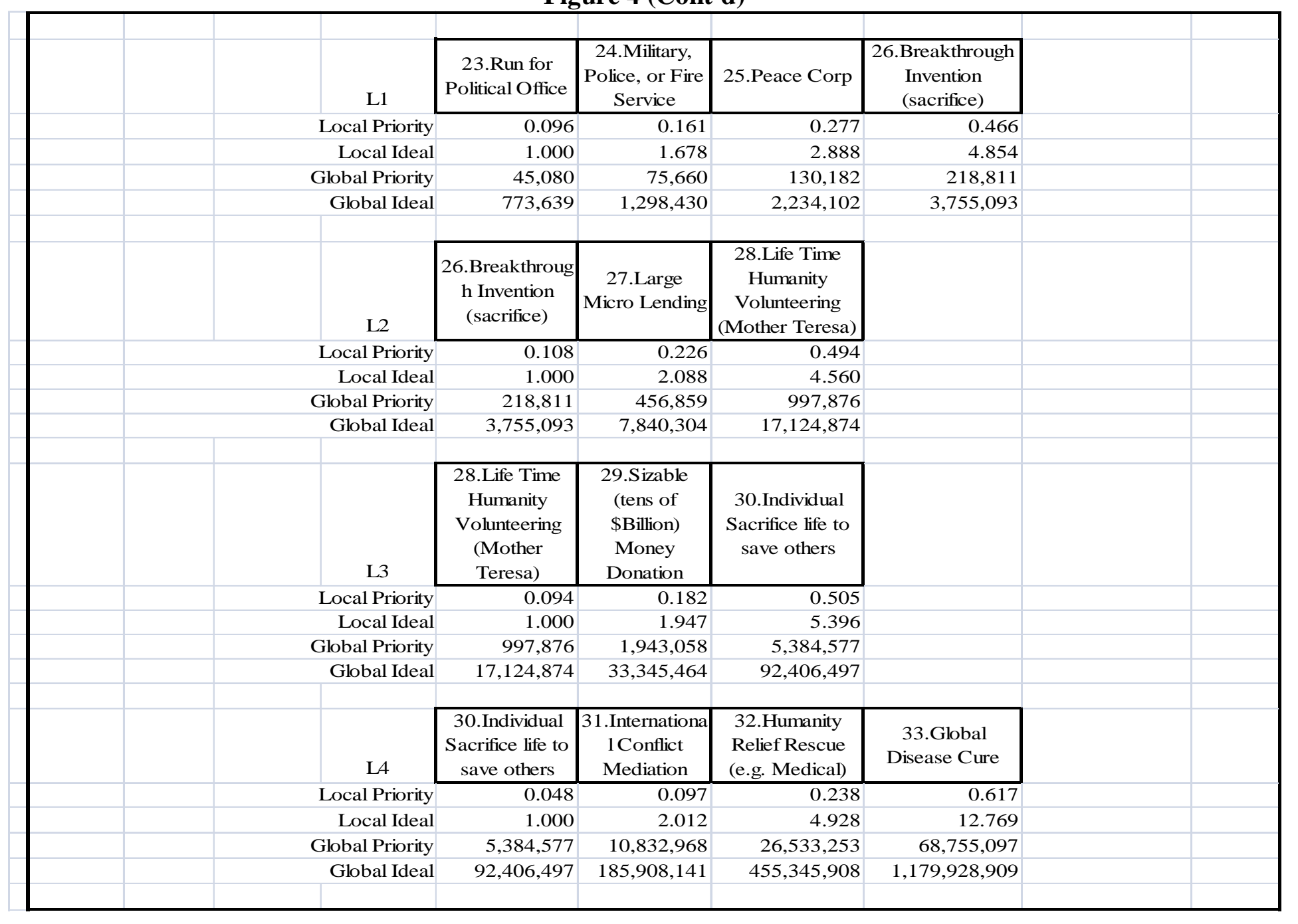


Figure 5. The Final Priorities of All Studied Benevolent Acts

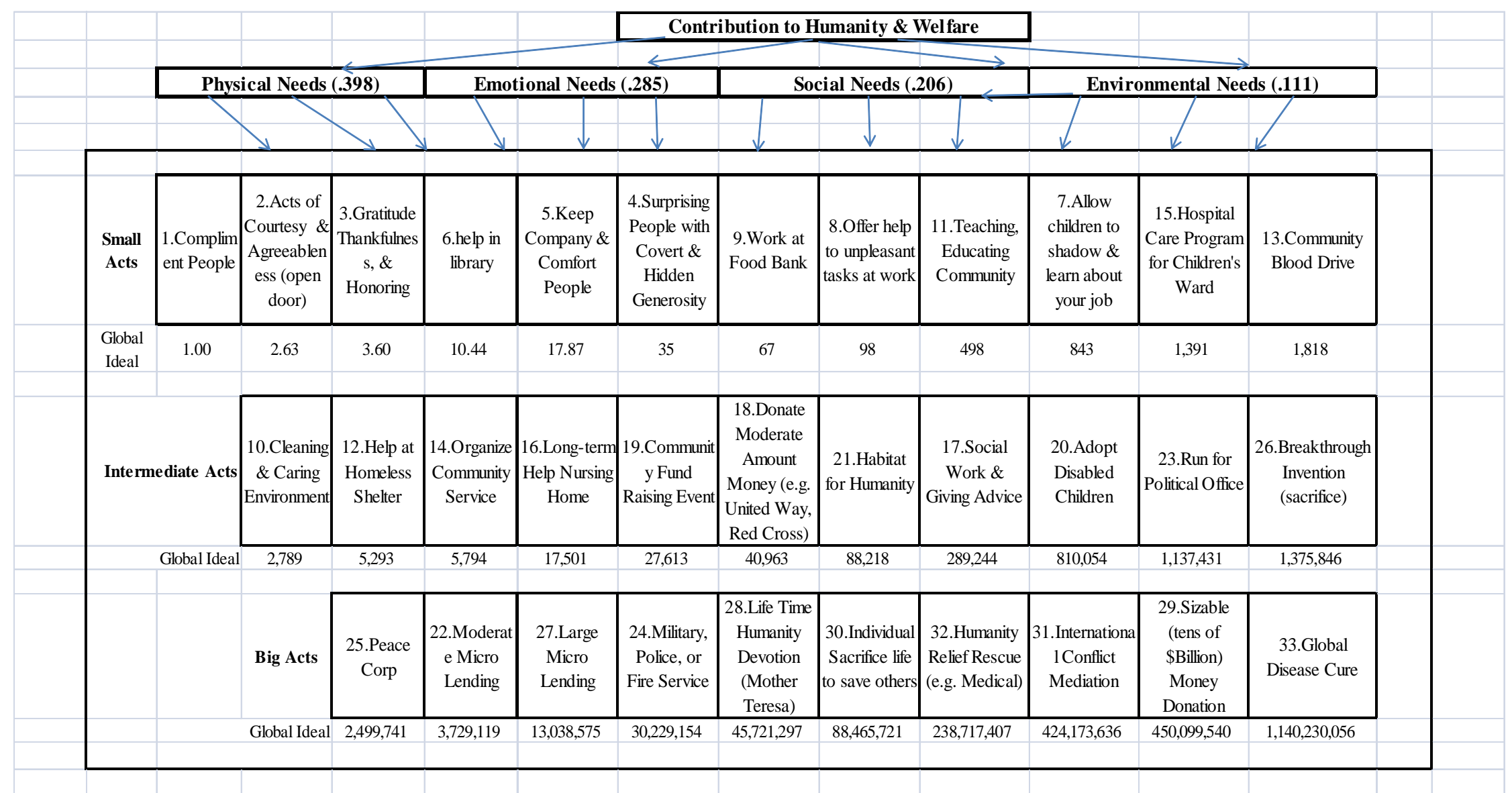

